\title{
Educação Ambiental: Teoria e Prática na Escola Estadual de Educação Básica Palmeira das Missões Projeto Pequenas Atitudes, Grandes Resultados
}

\author{
Environmental Education: Theory and Practice In the State School of Basic Education \\ Palmeira Mission Small Attitudes Project, Great Result \\ Cristiane Schneider Kuhn Stein ${ }^{1}$; Jorge Orlando Cuellar Noguera ${ }^{2}$ \\ ${ }^{1}$ Especialista em Educação Ambiental, aluna do Curso de Especialização em Educação Ambiental Polo UAB, Panambi, RS, \\ Brasil; ${ }^{2}$ Professor, Dr. Orientador, UFSM, RS, Brasil.
}

\section{Resumo}

Esta artigo é resultado da pesquisa realizada para a Monografia do Curso de Especialização em Educação Ambiental- UFSM, para a obtenção do grau em Especialista em Educação Ambiental. Teve como referência a análise do projeto "Pequenas Atitudes, Grandes Resultados" que foi realizado na Escola Estadual de Educação Básica Palmeira das Missões/Rio Grande do Sul. A escola está localizada na zona urbana do município de Palmeira das Missões, sendo desenvolvido com dois professores e 29 alunos de Ensino Médio. Como problemática, tivemos as contribuições e os desafios identificados por alunos e professores nas práticas de Educação Ambiental do Projeto. O objetivo geral consistiu em conhecer, analisar e avaliar os resultados, os desafios e as contribuições que foram identificados pelo sujeito da pesquisa. Neste sentido foi utilizado método investigativo e utilizada uma pesquisa qualitativa, que foi elaborado através de um estudo de caso. Para realizar o referencial teórico, foi utilizado Brasil (1965,1981,1986,1999); Reigota (2009), Gil (2002), entre outros. A partir do referencial teórico, foi analisado o projeto observando os pontos negativos e positivos do mesmo. O Projeto surgiu da necessidade da escola em trabalhar com assuntos relacionados á preservação do Meio Ambiente, procurando partir de problemáticas vividas no cotidiano da própria escola e da comunidade em que está inserida..

Palavras-chave: Meio Ambiente. Educação Ambiental. Resíduos Sólidos.

\section{Abstract}

This monograph was developed through the project "Small Attitudes , Great Results " which was held at the State School of Basic Education Palm Missions / Rio Grande do Sul. The school is located in the urban area of Palm Missions, being developed with two teachers and 29 high school students. As problematic had the contributions and challenges identified by students and teachers in the practices of the Environmental Education Project. The overall goal was to learn, analyze and evaluate the results, the challenges and the contributions that have been identified by the research subject. In this sense was used investigative method and used a qualitative research, which was prepared by in case study. The principal authors were worked Reigota and Gil, among others, where it was used theoretical foundation to support this work. From these thinkers analyzed the project noting the missing points and positive points of this project. That this project arose from the need to work with school related matters will preserve the environment, looking on their daily living from the school itself and the community in which it operates problematic.

Keywords: Environment. Environmental Education. Solid Waste. 


\section{Introdução}

Na monografia foi abordado os temas: Políticas públicas, Educação Ambiental no Brasil e Educação Ambiental no contexto escolar . Também foi realizada a análise de um Projeto de Educação Ambiental aplicado por uma escola da rede estadual de Ensino, no municipio de Palmeira das Missões.

O projeto "Pequenas Atitudes, Grandes Resultados" surgiu da necessidade da escola em trabalhar com assuntos relacionados á preservação do meio ambiente, procurando partir de problemáticas vividas no cotidiano da própria escola e da comunidade em que está inserida, sendo, portanto o presente projeto mencionado o objeto de análise que resultou esta pesquisa. $\mathrm{O}$ interesse pelo assunto surgiu da inquietude de saber a forma como foi surgiu o projeto na escola, assim como seu desenvolvimento e atividades realizadas, objetivando sua aplicação em outras comunidades.

A pesquisa realizada pelo grupo de educadores e educandos teve como objetivo trazer para a sala de aula e para a comunidade escolar uma reflexão sobre Meio Ambiente e Qualidade de Vida. Ao analisar o projeto como observador procurei conhecer a concepção dos alunos e professores e identificar as contribuições do trabalho desenvolvido na realidade em que estão inseridos e os principais desafios enfrentados pelos sujeitos da pesquisa. No decorrer da aplicabilidade do Projeto foram desencadeadas várias ações com os alunos e a comunidade.

O envolvimento de todos os segmentos foi à primeira ação concreta. Após realizarem diversas as ações observou-se a necessidade de conhecer e refletir sobre a destinação destes resíduos. Partiu-se para leitura de textos, participação em palestras, visitação do aterro sanitário do município. Estas ações dentre outras desenvolvidas pelos sujeitos participantes do projeto desencadearam inúmeras reflexões que vieram ao encontro das preocupações com as questões ambientais do nosso planeta como um todo, principalmente no que se refere à degradação dos ecossistemas, de como estas degradações estão atingindo a humanidade, em saber como estão sendo trabalhadas estas questões nos meios escolares do nosso país, pois se sabe que é também, através da Educação Ambiental que será construída a noção da necessidade desta preservação destes ecossistemas para a continuidade da vida neste planeta.

As inquietações que unem a Educação Ambiental e os bancos escolares levaram a necessidade de contextualizar a pergunta: quais as contribuições e os desafios identificados por professores e alunos do $3^{\circ}$ ano do Ensino Médio nas práticas de Educação Ambiental do Projeto "Pequenas Atitudes Grandes Resultados" na Escola Estadual de Educação Básica Palmeira das Missões?

\section{Revisão Bibliográfica}

As politicas públicas servem para organizar e normatizar todas as ações que precisam e devem ser tomadas com relação ao meio ambiente e tudo o que diz respeito a ele. A escola precisa conhecer estas políticas para também fundamentar as ações de seu projeto para que ele contribua para o objetivo principal que é ajudar de alguma forma a disseminar informações na comunidade escolar para que esta possa contribuir significativamente com a preservação do meio ambiente iniciando nas próprias casas dos envolvidos e consequentemente avançando para os demais membros da comunidade.

Após o fim da revolução industrial aumentou consideravelmente o consumismo, a sociedade passou a dar uma nova ênfase ao consumo, onde o desejo da compra e o prazer pelo poder ditava o comportamento do consumidor e foi com esta perspectiva que surgiram computadores, acessibilidade a carros, roupas, acessórios, eletrônicos dos mais diversos modelos e preços, então por acaso, segundo o dicionário a palavra "consumir" significa "extinguir" (RIOS, 2010, p.135).

Muitas leis tem surgido para esclarecer sobre a preservação do meio ambiente. Nesta pesquisa fez um recorte em algumas delas para poder analisar o Projeto da Escola.

A lei $\mathrm{n}^{\circ} 9.795$, de 27 de abril de 1999 nos artigos $1^{\circ}$ e $2^{\circ}$ traz conceitos e entendimentos sobre o que vem a ser Educação Ambiental.

Segundo Buarque (2013), a civilização industrial chegou ao século XXI como a civilização da produção e do lixo. Por um lado apresenta um imenso Produto Interno Bruto (PIB) de novos produtos a cada ano e por outro apresenta um imenso "anti-PIB", não apenas sob forma de depredação da natureza, mas também no contexto do lixo criado pelo processo de produção e de consumo.

Para Carvalho (2004), a educação ambiental,

nasce como um processo educativo que conduz a um saber ambiental materializado nos valores éticos e nas regras políticas de convívio social e de mercado, que implica a questão distributiva entre benefícios e prejuízos da apropriação e do uso da natureza. Ela deve, portanto, ser direcionada para a cidadania ativa considerando seu sentido de pertencimento e corresponsabilidade que, por meio da ação coletiva e organizada, busca a compreensão e a superação das causas estruturais e conjunturais dos problemas ambientais. Trata-se de construir uma cultura ecológica que compreenda natureza e sociedade como dimensões intrinsecamente relacionadas e que não podem mais ser pensadas — seja 
nas decisões governamentais, seja nas ações da sociedade civil- de forma separada, independente ou autônoma (CARVALHO, p. 2004).

A Educação Ambiental é mencionada no Brasil aproximadamente a partir de 1965, este registro está no Código Florestal instituído através da Lei 4.771, como nos mostra:

Art. 42. Dois anos depois da promulgação desta Lei, nenhuma autoridade poderá permitir a adoção de livros escolares de leitura que não contenham textos de educação florestal, previamente aprovado pelo Conselho Federal de Educação, ouvido o órgão florestal competente (BRASIL, 1965).

As escolas são mediadoras da aquisição do conhecimento e cabe a elas mobilizarem alunos e seus familiares sobre a importância e necessidade de conservação do meio ambiente. Como nos aponta Reigota (2009, p.45) a introdução ambiental na escola supõe uma modificação fundamental na própria concepção de educação, provoca mesmo uma revolução pedagógica. Segundo Vasconcellos (1997) a presença, em todas as práticas educativas, da reflexão sobre as relações dos seres entre si, do ser humano com ele mesmo e do ser humano com seus semelhantes é condição imprescindível para que a Educação Ambiental ocorra. Neste sentido, as escolas se colocam como espaços favoráveis para esta reflexão com atividades de sala de aulas, visitas e práticas que favoreçam a sensibilização e criem novos paradigmas.

\section{Metodologia}

O campo de pesquisa em questão foi o município de Palmeira das Missões que está localizado na região noroeste do Estado do Rio Grande do Sul. Possui uma área de $1.415,7 \mathrm{Km}^{2}$ e a população estimada é de 38.192 mil habitantes e uma densidade demográfica de 24,2 hab. $/ \mathrm{km}^{2}$ (PALMEIRA DAS MISSÕES, 2014).

O município conta segundo os dados do IBGE de 2012 com seis escolas que oferecem educação na modalidade de Ensino Médio. Dentre estas seis destaca-se a Escola Estadual de Educação Básica Palmeira das Missões referencial do desenvolvimento dos projetos do Ensino Médio Politécnico com o tema Meio Ambiente e Qualidade de Vida e mais especificamente conta com 47 professores, sendo dois os responsáveis pela organização e execução do projeto Pequenas Atitude, Grandes Resultados.

\section{A procura pela escola e professores}

Para o desenvolvimento desta pesquisa optou-se pela Escola Estadual de Educação Básica, com tradição, que fora representativa em quantidade e qualidade de alunos assim como sua qualificação na educação infantil e ensino médio politécnico, além destas características deveria ter parâmetros de atração nas áreas de ensino e cultura local. Observou-se também outras características como: se havia biblioteca e videoteca, laboratório de ciências, laboratório de informática e espaço físico.

\section{Elaboração e aplicação dos questionários aos educadores e educandos}

Dentre outras formas de análise dos dados destaco aqui a aplicação de questionários aos envolvidos no projeto sendo a forma mais eficiente de os mesmos realizarem suas declarações, expressarem seus pensamentos e opiniões de forma oculta. Já que expor opiniões ao grupo sobre temas polêmicos como a EA, nem sempre é possível. O questionário se estendeu a dois segmentos da escola ou seja aos professores e alunos.

\section{Análise e avaliação dos resultados}

Os questionários foram elaborados com seis questões dissertativas para ambos os segmentos, porém com questões distintas para os dois seguimentos. Sendo que foram dois questionários para educadores e vinte e nove questionários para educandos Os dados obtidos através dos questionários foram analisados e transformados em gráficos de acordo com as delimitações de cada questão, sendo seguidos de reflexões pertinentes a cada um deles. 


\section{A procura pela escola e professores}

A escola escolhida segundo os objetivos da pesquisa denomina-se Escola Estadual de Educação Básica Palmeira das Missões. Esta é carinhosamente chamada de "Polivalente", ou simplesmente "Poli", localizada na Rua Moisés da Silva Martins, número 164, no Bairro Portella, foi criada através do decreto $\mathrm{N}^{\mathrm{o}} 20590$ de 06 de outubro de 1970.

É nesta realidade onde se situa a escola e que com esforço de todos os segmentos em 1978 foi criada a banda escolar que atualmente é denominada Banda Marcial Polivalente e é composta por 40 alunos.

Atualmente a escola atende uma clientela de 824 alunos, distribuídos em 37 turmas da Educação Infantil ao Ensino Médio Politécnico e Curso de Enfermagem. Compõem o quadro funcional da escola 47 professores e 18 funcionários.

Os seus alunos são oriundos dos bairros Portella, Fátima, Vista Alegre, Seis de Maio, Batista, Witeck e também alunos vindos do interior do município. Possui um bom espaço físico onde conta com biblioteca e videoteca, laboratório de ciências, moderníssimo laboratório de enfermagem, laboratório de informática e ginásio de esportes coberto. Periodicamente são realizadas obras que primam pela recuperação, manutenção e melhoria desta infraestrutura.

É nesta realidade que se desenvolvem entre outros o projeto do Ensino Médio Politécnico com o tema Meio Ambiente e Qualidade de Vida e mais especificamente denominado "Pequenas Atitudes, Grandes Resultados" que vem a ser analisado por esta monografia.

Por trabalharem nesta perspectiva é que esta escola foi a escolhida entre as demais analisadas. Os seus educadores estão todos envolvidos em prol de um objetivo em comum, mas especificamente dois deles são os responsáveis pelo desenvolvimento do projeto mencionado e analisado. Sendo eles a fonte de inspiração dos alunos envolvidos e também suporte teórico básico para o desencadeamento de todas as ações que foram desenvolvidas.

As reflexões realizadas partiram principalmente após a análise das respostas dadas pelos professores idealizadores do projeto e dos educandos sujeitos participantes e executores do mesmo. Para tanto foi organizado um questionário para os educadores e um para os educandos. Com base na metodologia apresentada anteriormente, são apresentados a seguir os resultados obtidos com a pesquisa.

\section{Resultados da elaboração e aplicação dos questionários aos educadores e educandos}

Os educadores organizadores do projeto foram as referências base para os alunos diretamente envolvidos e também para os demais membros da comunidade escolar. Do decorrer da analise do projeto estes dois educadores responderam ao questionário, iniciou-se então a análise das respostas dos questionários aplicados aos educadores.

Dos educadores aplicados os questionários, $100 \%$ deles responderam e pode-se observar que ao avaliar o projeto com relação aos seus objetivos e se estes foram alcançados o educador 1 relatou que: "Muitos dos objetivos propostos foram atingidos por que conseguimos mobilizar a comunidade em relação às causas ambientais. Eles atenderam ao nosso chamado nas campanhas de recolhimento de medicamentos vencidos, resíduos eletrônicos e tóxicos (pilhas e baterias). Também estabelecer uma boa parceria com alguns agricultores, em função da recuperação de APPs com o fornecimento de mudas de arvores nativas, produzidas a partir do adubo orgânico oriundo da compostagem feita na própria escola"

Mesmo com tantos resultados positivos algumas dificuldades também foram encontradas e isso se pode observar pelo comentário a seguir: "Falta de comprometimento nos diferentes segmentos, principalmente com os funcionários da escola, pois estes acreditam que o projeto tem um prazo. A cada final de trimestre eles nos perguntam se já podem misturar o lixo. Este tema é tido como chato por uma boa parcela dos envolvidos, pois exige envolvimento pessoal, disciplina e reeducação (PROFESSOR 1). Já o professor 2 relatou que: " as dificuldades situaram-se no momento da "práxis", visto que a mudança está no campo das atitudes individuais e isto ficou evidente que o "novo" causa e dinamiza iniciativas muitas vezes ambíguas ao "velho".

Ao final de cada trimestre os membros participantes do projeto avaliam suas ações e por enquanto destacaram cinco pontos relevantes que fizeram o projeto ter continuidade. Considero de fundamental importância mencioná-los para percebermos a efetiva relação entre os conhecimentos teóricos e os conhecimentos práticos, bem como as reflexões que se desencadearam devido à fusão dos dois. A escola passou reaproveitar melhor os materiais de uso comum; grande parte das famílias começaram a separar o lixo; parceria entre a escola e alguns agricultores para a reposição de plantas nativas em áreas desmatadas; reflexão na escola em torno dos recursos naturais; reflexão na comunidade sobre os riscos de contaminação do solo e água através do descarte inadequado dos resíduos (medicamentos, eletrônicos, pilhas, baterias). 
Também sobre as contribuições do projeto para a escola e a sociedade palmeirense, destaca-se as palavras do educador 2 quando nos diz que: " a nível de escola foi de extrema importância visto que o projeto realizado durante a disciplina de Seminário Integrado e realizado pelas perspectivas das necessidades dos educandos. [...] Portanto não só a nível de escola foi de suma importância mas no momento em que o projeto tem a participação de toda a comunidade escolar, consequentemente ultrapassa os "muros" escolares e iniciando com o educando em seu lar e comunidade ter atitudes realizadas durante o horário escolar".

Os educandos da atualidade exigem cada vez mais de seus educadores. As aulas somente com o quadro de giz e a fala do educador já deixou de ser atrativa a muito tempo. O ensino politécnico e esta forma de aprender através de projetos vem ao encontro de superar aquelas aulas tradicionais e tentar atrair os alunos a refletirem sobre os problemas da atualidade e sua capacidade de agir diante deles.

Pensando desta forma aplicou-se também aos educandos um questionário para analisar o que eles apreenderam com as vivencias desenvolvidas a partir do desenvolvimento do projeto. Atingimos assim um número de 29 alunos que representa $100 \%$ dos alunos envolvidos.

Apresenta-se também uma análise dos questionários aplicados aos educandos para que se possa conhecer e verificar o envolvimento dos mesmos com o projeto. Para isso foi aplicado a eles seis questões.

Com relação à questão1 - Conhecia o problema do projeto Pequenas Atitudes, Grandes Resultados? $100 \%$ dos entrevistados conheciam o problema do projeto através de pesquisas, de estudos, enfim, aprofundaram seus conhecimentos a partir da orientação dos educadores responsáveis.

Quanto a questão 2 que tratava de conhecer o objetivo geral e os específicos envolvidos no projeto, $99 \%$ dos entrevistados conheciam o objetivo geral e os específicos do projeto, pois eles ajudaram no planejamento, no desenvolvimento e na execução.

Referente a questão 3 que versava sobre a metodologia utilizada para desenvolver as ações do projeto, $95 \%$ dos entrevistados afirmaram que receberam orientação dos educadores já que não dominavam este tema.

No que se refere à questão 4 que trata de avaliar o projeto destaca-se os seguintes percentuais: $20 \%$ dos alunos responderam que os professores realizaram a avaliação; $40 \%$ responderam que ocorreu o que eles denominaram de auto avaliação; $25 \%$ responderam que a avaliação ocorreu no final de cada trimestre e os $15 \%$ restantes responderam que a avaliação aconteceu no final do ano. Confira os dados no gráfico 1 Avaliação do Projeto.

\section{Avaliação do Projeto}

$\begin{array}{ll}\text { - Avaliação no final do ano } & \text { Avaliação no final do Trimestre } \\ \text { Professores avaliaram } & \text { Se auto avaliaram }\end{array}$

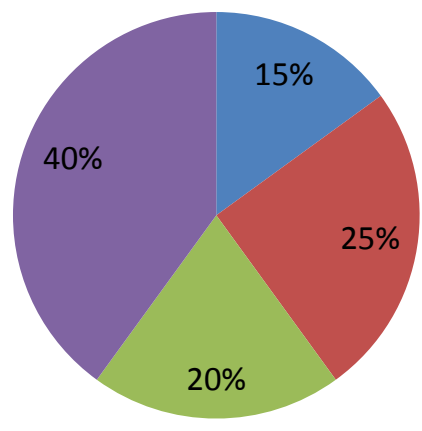

Gráfico 1 - Avaliação do Projeto

Fonte: Pesquisa de Campo realizada pela Autora desta pesquisa, 2014.

O que se observou nesta questão e que merece destaque é que os alunos não possuem um esclarecimento sobre o que realmente é avaliar um projeto, tanto que confundiram a avaliação do mesmo, com sua avaliação individual.

A questão de número 5 tratou dos conhecimentos construídos através do projeto e merecem destaque aqui quatro assuntos levantados pelos educandos, são eles: descarte correto dos resíduos sólidos, plantio de árvores nativas, nova forma de apresentar trabalhos e perceber e interpretar a realidade. O percentual de cada item pode ser visto no gráfico que segue. 


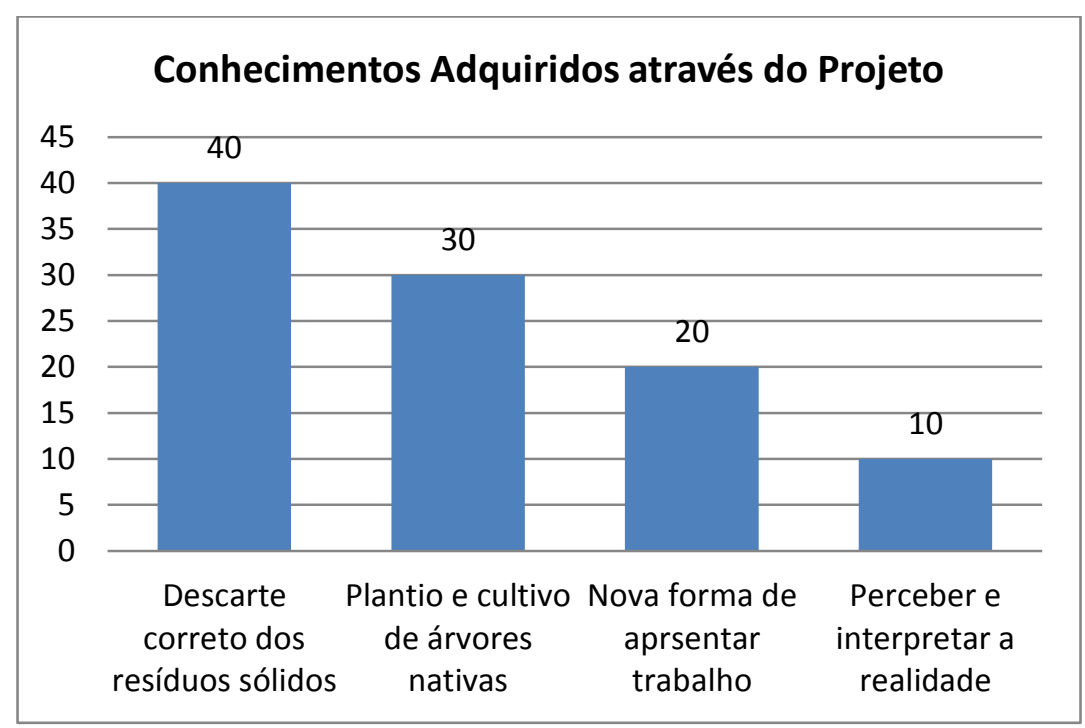

Gráfico 2 - Conhecimentos construídos através do Projeto

Fonte: Pesquisa de Campo realizada pela Autora desta pesquisa, 2014.

Com um percentual de $40 \%$ dos entrevistados passaram a observar e a se preocupar com o descarte correto de resíduos sólidos dando ainda ênfase ao lixo hospitalar; 30\% destacaram os conhecimentos adquiridos com relação ao plantio e o cultivo de árvores nativas aqui do estado, principalmente com a utilização do adubo orgânico produzido na própria escola através da compostagem, uma das ações realizadas para a destinação correta do lixo orgânico produzido na própria escola; $20 \%$ destacaram a nova forma de organizar o trabalho e sua apresentação para os demais colegas e $10 \%$ afirmaram que o mais significativo foi perceber e interferir nos problemas da própria escola e da comunidade em que ela está inserida.

No gráfico 3 - pode ser visualizado o percentual das contribuições do projeto para a escola e para a sociedade palmeirense.

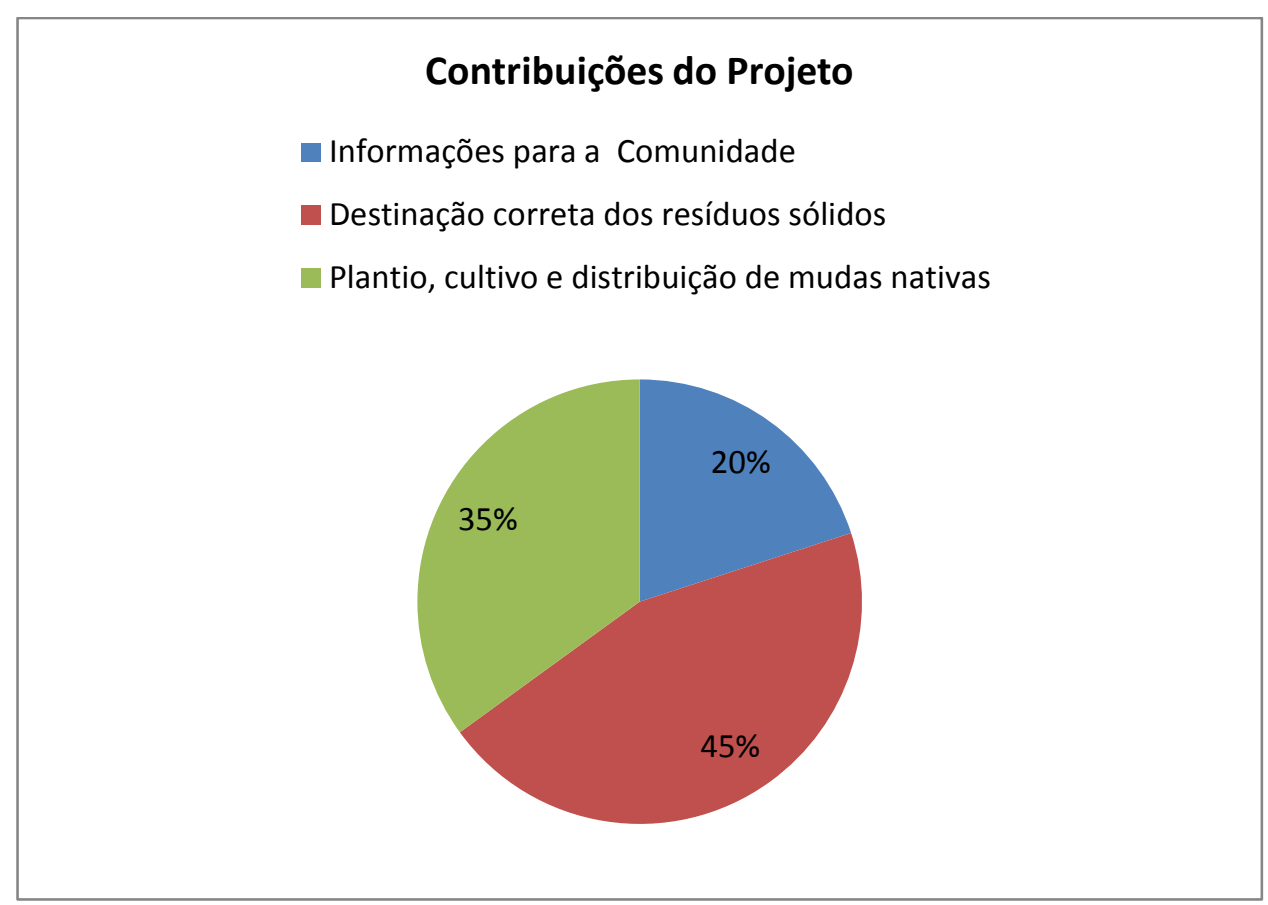

Gráfico 3 - Contribuições do Projeto

Fonte: Pesquisa de Campo realizada pela Autora desta pesquisa, 2014.

Podem-se destacar os seguintes percentuais: $45 \%$ dos entrevistados mencionaram o recolhimento e correta destinação dos resíduos sólidos como contribuição significativa para a comunidade; 35\% destacaram o plantio, cultivo e distribuição de mudas de árvores nativas para a comunidade como maior 
contribuição para a comunidade e $20 \%$ destacaram as informações repassadas à comunidade sobre os temas abordados como ponto relevante.

Ao analisar todos os questionamentos e todas as suas respostas pode-se perceber que a maioria dos educandos se envolveu significativamente em todas as etapas do projeto, mas que a que mais lhes proporcionou a construção do conhecimento de forma significativa foram às ações práticas desenvolvidas diretamente com a comunidade escolar e também fora dela.

\section{Consequências da análise e avaliação dos resultados}

O projeto desencadeou um círculo de ações que envolveram todos os segmentos que compõe a comunidade escolar.

O segmento dos funcionários foi o que mais resistiu e ainda resiste em por em prática a separação do lixo, mas nem esta resistência desanimou os propositores, pelo contrário, os motivou ainda mais a provar que estavam certos em querer a separação dos resíduos.

Duas ações concretas se destacaram diante de inúmeras outras pequenas ações executadas diariamente, são elas: a coleta, separação e correta destinação dos resíduos sólidos produzidos pela própria escola e o plantio, cultivo e distribuição de mudas de árvores nativas para a comunidade palmeirense.

Percebe-se ainda a reflexão sobre diversos temas e a desinquietação diante de ações incorretas. As sementes mais preciosas plantadas, além daquelas sementes de mudas de árvores nativas. Sementes plantadas em cada um dos alunos responsáveis pelo projeto e em todos aqueles que de uma forma ou outra se envolveram. Essa sim foi e continuará sendo o grande legado deste projeto.

\section{Conclusões}

Esta pesquisa foi desenvolvida a partir da análise do Projeto "Pequenas Atitudes, Grandes Resultados" executado pela Escola Estadual de Educação Básica Palmeira das Missões/Rio Grande do Sul, com a colaboração de uma turma de 29 alunos do $3^{\circ}$ ano do Ensino Médio e dois de seus professores.

Estes dois educadores, primeiramente tiveram o desafio de despertar em seus 29 educandos o desejo de pesquisar e conhecer o tema proposto e depois ainda enfrentaram o desafio de mobilizar toda uma escola em busca de conhecer mais sobre um problema tão presente em nossa sociedade que é a destinação incorreta dos resíduos sólidos.

As inquietações oriundas dos problemas ambientais unem a Educação Ambiental e os bancos escolares esta união deu origem a pergunta: quais as contribuições e os desafios identificados por professores e alunos do $3^{\circ}$ ano do Ensino Médio nas práticas de Educação Ambiental do Projeto "Pequenas Atitudes Grandes Resultados" na Escola Estadual de Educação Básica Palmeira das Missões?

Para responder a este questionamento o projeto norteou sua pesquisa com base em três objetivos que são: Procurar a escola e professores; Elaborar e aplicar os questionários aos educadores e educandos; Analisar e avaliar dos resultados; Todos os objetivos foram atingidos e desencadearam as analises apresentadas anteriormente.

Os resultados observados a partir da análise do projeto e de suas ações concretas destacam quatro pontos relevantes sendo eles: o melhor reaproveitamento dos materiais de uso comum. As maiorias das famílias começaram a separar o lixo. O início da parceria entre a escola e alguns agricultores para a reposição de plantas nativas em áreas desmatadas. Desencadeamento de diversas reflexões na escola em torno dos recursos naturais.

As mudas de árvores nativas que foram e ainda serão plantadas pelos agricultores serão um presente para a comunidade em geral. Esta ação trará benefícios não só para esta geração, mas também as gerações futuras. E todo o conhecimento construído será passado de geração em geração quando alguém questionar: porque esta árvore foi plantada aqui? E quando alguém responder.

Dentre estas, duas ações concretas se destacaram: a coleta, separação e correta destinação dos resíduos sólidos produzidos pela própria escola e o plantio, cultivo e distribuição de mudas de árvores nativas para a comunidade palmeirense.

Ao aprofundar os estudos dentro da área da EA se observa cada vez mais o potencial desta em conseguir alertar para os problemas ambientais existentes na sociedade atualmente, sendo ela uma das únicas e últimas esperanças que temos para recuperar o que resta do nosso meio ambiente.

Os resultados obtidos foram tão positivos que outras escolas deveriam se apropriar desta trajetória traçada pela Escola de Educação Básica Palmeira das Missões e também possibilitar a seus educandos refletir e agir diante desta realidade dos resíduos sólidos mal destinados. Deixo aqui o desafio para que uma nova proposta surja para que os educandos possam ser os monitores destas reflexões em outras escolas, palestrando sobre o que desenvolveram e aprenderam. 
Percebe-se na reflexão sobre diversos temas a desinquietação diante de ações incorretas, estas sem dúvida foram as sementes mais preciosas plantadas, não somente aquelas sementes de mudas de árvores nativas. Sementes plantadas em cada um dos alunos responsáveis pelo projeto e em todos aqueles que de uma forma ou outra se envolveram. Esse sim foi e continuará sendo o grande legado deste projeto.

\section{Referências}

BRASIL. Constituição (1988). Constituição da República Federativa do Brasil: Promulgada em 5 de outubro de 1988: atualizada até a Emenda Constitucional n. 20, de 15-12-1998. 21. ed. São Paulo: Saraiva, 1999.

$\begin{array}{llll}\text { BRASIL. Código } & \text { Florestal, } & 1965 . & \text { Disponível }\end{array}$ em:<http://www.planalto.gov.br/ccivil 03/leis/14771.htm>. Acesso em: 14 jan. 2015.

BRASIL. Lei 6.938. Disponível em: http://www.sema.rs.gov.br/upload/Lei\%20Federal\%20n\%C2\%BA\%206938_1981.pdf. Acesso em: 22 fev. 2015.

Brasil. Lei $\mathrm{n}^{\mathrm{o}}$ 9.795, de 27 de abril de 1999. Disponível em: <http://www.planalto.gov.br/ccivil 03/leis/19795.htm>. Acesso em: 12 jan. 2015.

BUARQUE, Cristovam. Desafio à humanidade: perguntas para a Rio +20. Rio de Janeiro: Saberes, 2013. 1998.

CURRIE, K. L. Meio Ambiente: interdisciplinaridade na prática. Campinas: Papirus. 184p.

DIAS, Genebaldo Freire. Ecologia Geral. São Paulo: Vozes, 1994.

Genebaldo Freire. Educação Ambiental: princípios e práticas. São Paulo: Gaia. 1994. Presidência da República. Casa Civil. Subchefia para Assuntos Jurídicos.

FARIAS, Talden Queiroz. Evolução histórica da legislação ambiental. In: Âmbito Jurídico, Rio Grande, X, n.39, mar/2007. Disponível: $<$ http://www.ambitojuridico.com.br/site/index.php?n link=revista artigos leitura\&artigo id=3845 $>$. Acesso em: set. 2014.

GIL, Antônio Carlos. Como elaborar projetos de pesquisa. São Paulo: Atlas, 2002.

JACOBI, Pedro Roberto (org.) Cad. Cedes, Campinas, vol. 29, n. 77, p. 63-79, jan./abr. 2009. Disponível em: <http://www.cedes.unicamp.br>. Acesso em: dez de 2014.

LOUREDO, Paula. Educação Ambiental e os 5R. Disponível em: $<$ http://educador.brasilescola.com/estrategias-ensino/educacao-ambiental-os-5-rs.htm acesso em 09/09/2014>. Acesso em: dez de 2014.

MENDONÇA, Patrícia Ramos. TRAJBER, Rachel (org.) Educação na diversidade: o que fazem as escolas que dizem que fazem educação ambiental. Brasília: Secretaria de Educação Continuada, Alfabetização e Diversidade, 2006.

PALMEIRA DAS MISSÕES. Dados Gerais sobre o Município. Disponível em $<$ http://www.palmeiradasmissoes-rs.com.br/>. Acesso em: 30 set. 2014.

PROJETO "PEQUENAS ATITUDES, GRANDES RESULTADOS" DA ESCOLA ESTADUAL DE EDUCAÇÃO BÁSICA PALMEIRA DAS MISSÕES/RIO GRANDE DO SUL (Projeto analisado nesta monografia).

PROPOSTA PEDAGÓGICA PARA O ENSINO MÉDIO POLITÉCNICO E EDUCAÇÃO PROFISSIONAL INTEGRADA AO ENSINO MÉDIO, p.13, 2011. Disponível na Escola onde foi realizada a Pesquisa. Palmeira das Missões - RS. 
REIGOTA, Marcos. O que é educação ambiental. São Paulo: Brasiliense, 2009.

VASCONCELLOS, H. S. R. A pesquisa-ação em projetos de Educação Ambiental. Disponível em: <http://www.planalto.gov.br/ccivil 03/leis/19795.htm>. Acesso em: 10 dez. 2014. 